\title{
Evaluation of the Magicplex Real-Time Test for the Rapid Diagnosis of Bloodstream Infections in Adults
}

\section{OPEN ACCESS}

Edited by:

Bing Gu,

Affiliated Hospital of Xuzhou Medical

College, China

Reviewed by:

Krisztina M. Papp-Wallace, Louis Stokes Cleveland VA Medical

Center, United States Kevin Alby,

University of Pennsylvania, United States

Peter Michael Keller,

Universität Bern, Switzerland

*Correspondence: Catia Cillóniz

catiacilloniz@yahoo.com; cilloniz@clinic.cat

†These authors have contributed equally to this work

Specialty section: This article was submitted to

Clinical Microbiology,

a section of the journal

Frontiers in Cellular and Infection Microbiology

Received: 18 December 2018 Accepted: 20 February 2019 Published: 12 March 2019

Citation:

Zboromyrska Y, Cillóniz $C$

Cobos-Trigueros N, Almela M, Hurtado JC, Vergara A, Mata C, Soriano A, Mensa J, Marco F and Vila J (2019) Evaluation of the Magicplex ${ }^{T M}$ Sepsis Real-Time Test

for the Rapid Diagnosis of Bloodstream Infections in Adults. Front. Cell. Infect. Microbiol. 9:56. doi: 10.3389/fcimb.2019.00056

\begin{abstract}
Yuliya Zboromyrska ${ }^{1 \dagger}$, Catia Cillóniz ${ }^{2 \star \dagger}$, Nazaret Cobos-Trigueros $^{3}$, Manel Almela ${ }^{1}$, Juan Carlos Hurtado ${ }^{4}$, Andrea Vergara ${ }^{4}$, Caterina Mata ${ }^{5}$, Alex Soriano ${ }^{3}$, Josep Mensa ${ }^{3}$, Francesc Marco ${ }^{4}$ and Jordi Vila ${ }^{4}$

${ }^{1}$ The Consortium of the Intercomarcal Laboratory of the Alt Penedès, Department of Microbiology, Vilafranca del Penedès, Spain, ${ }^{2}$ Department of Pneumology, Hospital Clinic of Barcelona, Institut d'Investigacions Biomèdiques August Pi i Sunyer (IDIBAPS), Networked Biomedical Research Center for Respiratory Diseases (CIBERES), University of Barcelona, Barcelona, Spain, ${ }^{3}$ Department of Infectious Diseases, Hospital Clinic, University of Barcelona, Barcelona, Spain, ${ }^{4}$ Department of Microbiology, ISGlobal, Barcelona Centre for International Health Research, Hospital Clinic, University of Barcelona, Barcelona, Spain, ${ }^{5}$ Sample Preparation Team, Centre Nacional d'Anàlisi Genòmica, Parc Científic de Barcelona - Torre I, Barcelona, Spain
\end{abstract}

Sepsis is a serious health condition worldwide, affecting more than 30 million people globally each year. Blood culture (BC) is generally used to diagnose sepsis because of the low quantity of microbes occurring in the blood during such infections. However, 50\% of bloodstream infections (BSI) give negative BC, this figure being higher for sepsis, which delays the start of appropriate antimicrobial therapy. This prospective study evaluated a multiplex real-time polymerase chain reaction, the Magicplex ${ }^{\mathrm{TM}}$ Sepsis test (MP), for the detection of pathogens from whole blood, comparing it to routine BC. We analyzed 809 blood samples from 636 adult patients, with 132/809 (16.3\%) of the samples positive for one or more relevant microorganism according to $\mathrm{BC}$ and/or MP. The sensitivity and specificity of MP were 29 and 95\%, respectively, while the level of agreement between $\mathrm{BC}$ and MP was $87 \%$. The rate of contaminated samples was higher for BC (10\%) than MP (4.8\%) $(P<0.001)$. Patients with only MP-positive samples were more likely to be on antimicrobial treatment (47\%) than those with only BC-positive samples (18\%) $(P=0.002)$. In summary, the MP test could be useful in some clinical setting, such as among patients on antibiotic therapy. Nevertheless, a low sensitivity demonstrated impairs its use as a part of a routine diagnostic algorithm.

Keywords: bloodstream infection, PCR-based assay, blood culture, Magicplex ${ }^{\mathrm{TM}}$ Sepsis test, infection, sepsis

\section{INTRODUCTION}

The World Health Organization (WHO) in 2017 adopted a resolution on sepsis: "improving the prevention, diagnosis and clinical management of sepsis" (World Health Organization, 2018). Blood culture (BC) is generally used to diagnose sepsis because of the low quantity of microbes occurring in the blood during such infections. However, $\sim 50 \%$ of bloodstream infections (BSI) give negative $\mathrm{BC}$, this figure being higher for sepsis, which delays the start of appropriate antimicrobial therapy and consequently results in worse outcomes and higher mortality rates (Kumar et al., 2006; Ferrer et al., 2014). Prompt microbiological diagnosis enables a more appropriate antimicrobial 
treatment than the empirical combination of broad-spectrum antibiotics that have negative effects such as an increased prevalence of resistant pathogens (Candel et al., 2018). The microbial diagnosis of sepsis by $\mathrm{BC}$ has two main advantages: first, it allows the growth of very small numbers of the microorganism, which is important since the concentration of bacteria in the blood of septic adult patients is usually low $(<10$ CFU/mL) (Yagupsky and Nolte, 1990); second, this technique allows the isolation of pathogens and, hence, antimicrobial susceptibility testing can be performed. However, BC also has limitations that do not make it an ideal gold standard test, including the long time required for growth detection, the frequent false negative results in patients receiving antimicrobial therapy, and the inability to detect fastidious microorganisms (Sinha et al., 2018) which can delay the initiation of an adequate antimicrobial therapy and consequently results in worse outcomes and higher mortality rates (Kumar et al., 2006; Ferrer et al., 2014). Molecular tests offer important advantages over BC that could improve the diagnosis of BSI, such as the lower amount of time taken to obtain results by working directly from blood. In addition, the low detection limits of molecular assays might make them more sensitive than $\mathrm{BC}$, enabling the detection of fastidious, non-viable or non-culturable microorganisms, even from patients on antibiotic treatment (Fenollar and Raoult, 2007; Leitner et al., 2013; Sinha et al., 2018).

Another advantage of molecular assays is the ability to detect some specific resistance markers, which can provide important information for better treatment. Moreover, the rapid identification of the microorganism can be used to infer antimicrobial susceptibility according to local epidemiology.

The Magicplex ${ }^{\mathrm{TM}}$ Sepsis test (MP) (Seegene, Seoul, South Korea) is a multiplex real-time polymerase chain reaction (PCR) that detects more than 90 microorganisms at the genus level (73 Gram-positive bacteria, 12 Gram-negative bacteria and 6 fungi), 27 at the species level and 3 drug-resistant genes (mecA, vanA, and $v a n B$ ) within $6 \mathrm{~h}$. In this study, we evaluated the ability of the MP test to rapidly detect pathogens causing BSI in adult patients from whole blood compared to conventional BC.

\section{METHODS}

\section{Setting, Data, and Sample Collection}

The study was approved by the Ethics Committee of the Hospital Clinic of Barcelona (study no. 2011/6613). Written informed consent was waived because of the non-interventional study design.

Paired BC and $1 \mathrm{ml}$ samples of whole blood in an EDTA tube were obtained from adult patients $(\geq 18$ years old) from the Hospital Clinic of Barcelona, a 700-bed university hospital in Barcelona, Spain, from May to September 2011.

Samples were obtained from patients with suspected BSI and who met the criteria for BC collection. Samples were processed in parallel by MP and BC. Blood samples for MP and BC were obtained simultaneously from the same catheter or venipuncture. For each case, additional clinical data about ongoing antibiotic treatment, the suspected source of infection, as well as the results of other microbiological tests were collected.

\section{Routine Microbiological Techniques}

BC was incubated in a Bactec $9240{ }^{\circledR}$ (Becton Dickinson, MD, USA) for a maximum of 5 days. The following bottles were used: the resin-containing BACTEC Plus Aerobic/F and BACTEC Plus Anaerobic/F, and the non-resin-containing BACTEC Standard/10 Aerobic/F and BACTEC Lytic/10 Anaerobic/F. For positive samples, Gram staining and culturing on solid media were performed. Microorganisms were identified using matrix-assisted laser desorption/ionization time-of-flight mass spectrometry (MALDI-TOF MS) (Bruker Daltonics, Bremen, Germany). Routine susceptibility testing included the Phoenix ${ }^{\text {TM }}$ system (Becton Dickinson, MD, USA), Etest (AB bioMérieux), microdilution (Sensititre, Trek Diagnostic Systems, Inc., Westlake, Ohio, USA) and disc diffusion tests, depending on the pathogen isolated. Determination of the isolates as contaminants or pathogens was achieved by combining the clinical setting, pathogenicity of the isolated microorganisms and the number of positive $\mathrm{BC}$ bottles in the case of potential skin contaminants, such as coagulase-negative staphylococci (CoNS). CoNS were considered pathogens if the same species was detected in both sets of BC showing the same antimicrobial susceptibility pattern. Samples with positive BC for pathogens not included in the MP panel were excluded from the analysis.

\section{The Magicplex ${ }^{\mathrm{TM}}$ Sepsis Test (MP)}

Blood samples were initially pre-treated with the Seegene Blood Pathogen $\mathrm{Kit}^{\mathrm{T}}{ }^{\mathrm{T}}$, according to the manufacturer's instructions. This pre-treatment included the following steps: lysis of human cells with CM buffer, degradation of released DNA with MolDNase B, concentration by centrifugation of microorganisms and, finally, lysis of cells and release of nucleic acid. Bacterial DNA was automatically extracted and purified with the SeePrep $12^{\mathrm{TM}}$ extractor (Seegene). Amplification, screening and identification were performed following the manufacturer's instructions. Each sample was first processed by two conventional PCRs performed in two separate tubes: one for the detection of Gram-positive bacteria and resistance genes, and the other for Gram-negative bacteria (GNB) and fungi (Figure 1).

For this step the thermal cycler System 9700, Applied Biosystems was used. The first real-time PCR for screening was performed in three separate tubes, allowing the identification of pathogens at the genus or group level: Streptococcus spp., Staphylococcus spp., Enterococcus spp., GNB group A or B, fungi and 3 resistance genes (vanA, vanB, and $m e c A)$. For positive results, the second real-time PCR was carried out, allowing the identification of 27 pathogens at the species level, including 3 Streptococcus spp. (Streptococcus pneumoniae, Streptococcus agalactiae and Streptococcus pyogenes), 3 Enterococcus spp. (Enterococcus faecalis, Enterococcus faecium and Enterococcus gallinarum), 3 Staphylococcus spp. (Staphylococcus epidermidis, Staphylococcus haemolyticus and Staphylococcus aureus), 6 GNB from group A (Pseudomonas aeruginosa, Acinetobacter baumannii, Stenotrophomonas maltophilia, Serratia marcescens, Bacteroides fragilis, and Salmonella typhi), 6 GNB from group B (Klebsiella pneumoniae, Klebsiella oxytoca, Proteus mirabilis, Escherichia coli, Enterobacter cloacae, and Enterobacter 


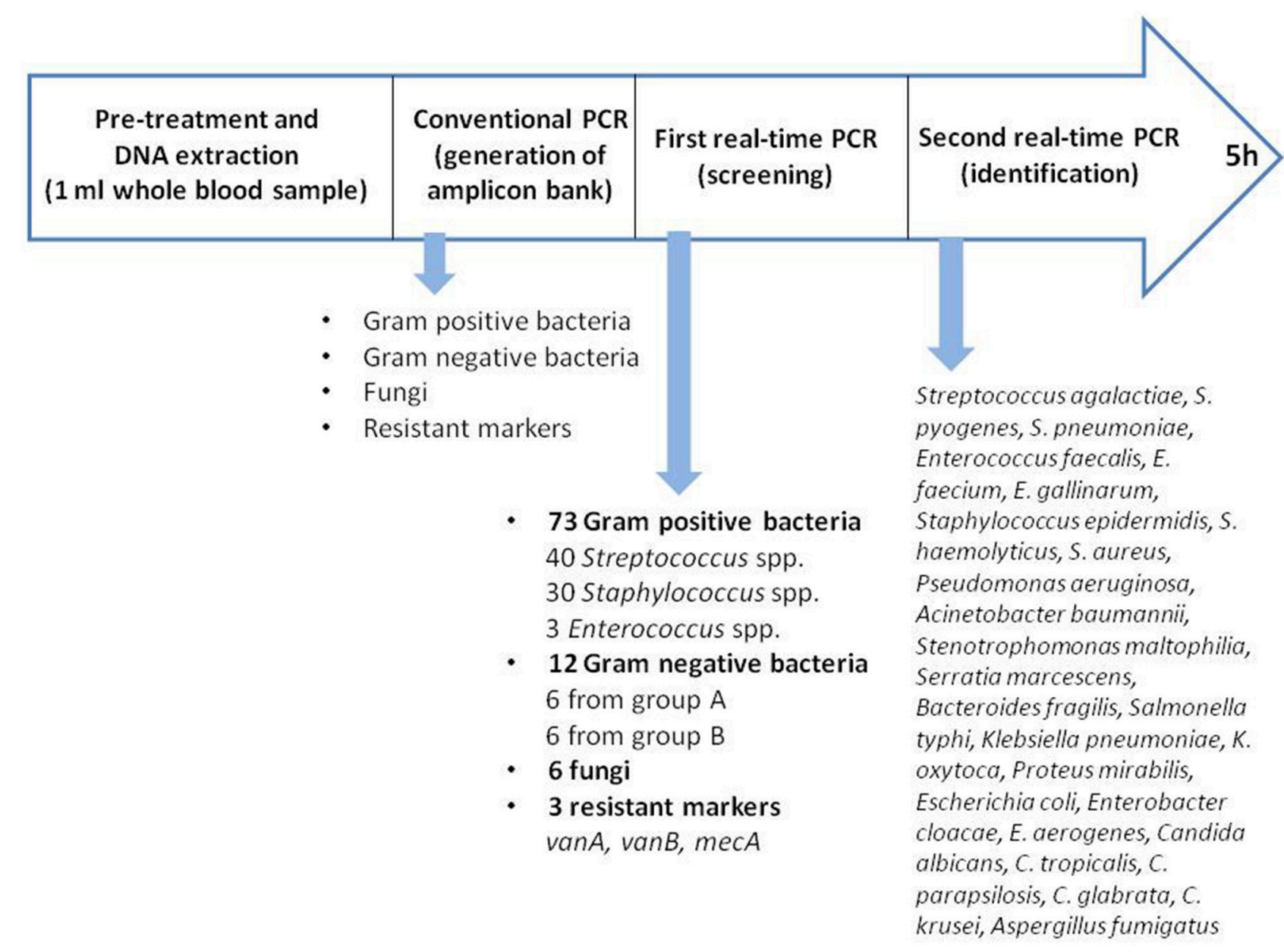

FIGURE 1 | Process of Magicplex ${ }^{T M}$ sepsis.

aerogenes), and 6 fungi (Candida albicans, Candida parapsilosis, Candida glabrata, Candida tropicalis, Candida krusei, and Aspergillus fumigatus). The real-time PCR were performed using the Cepheid SmartCycler.

The Seegene Viewer software was used to interpret the results, which were available within $6 \mathrm{~h}$. All the samples were stored at $2-8^{\circ} \mathrm{C}$ and processed within $24 \mathrm{~h}$ after collection.

MP samples positive for CoNS were considered to be true positives if the same microorganism was detected in two sets of BC. Samples that were positive according to MP in the first real-time PCR screening and identified only at the group level (e.g., GNB group A), but negative in the second real time-PCR were considered negative according to MP. To avoid confusing calculation in sensitivity and specificity we consider samples with only contaminants detected by MP and/or BC as negative. Internal control is included in each PCR step. Microorganisms identified by MP only at the genus level, such as Staphylococcus spp. and Streptococcus spp., were considered to be contaminants if the $\mathrm{BC}$ was negative or positive for staphylococci or streptococci that could be identified by MP at the species level.

\section{Statistical Analysis}

Categorical variables were compared using the chi-square test. To calculate the yield of the test, we analyzed sensitivity and specificity, and predictive values. All statistical comparisons were two-sided hypothesis tests, and the significance level was set at 0.05 . All confidence intervals (CIs) were two-sided at $95 \%$ confidence level. All analyses were performed with IBM SPSS Statistics 22.0 (Armonk, New York).

\section{RESULTS}

A total of 809 samples from 636 adult patients were collected and analyzed. Among the samples, 435 out of 809 (54\%) were from the emergency wards, 197 (24\%) from intensive care units (ICUs) and surgery, 159 (20\%) from oncology and hematology wards, and 18 (2\%) from other medical wards. The average age of patients was $56.7 \pm 5.6 ; 43 \%$ were females.

A total of 140 pathogens were detected among 132 positive samples (Table 1). E. coli was the most frequently detected 
TABLE 1 | Comparison of microbiological results between BC and MP.

\begin{tabular}{|c|c|c|c|c|c|}
\hline Pathogens detected & Positive only BC & Positive only MP & Positive both methods & Total, $\boldsymbol{n}(\%)$ & Prevalence among 809 samples, \% \\
\hline Escherichia coli & 27 & 15 & 5 & $47(34)$ & 5.8 \\
\hline CoNS & 7 & 0 & 9 & $16(11)$ & 2 \\
\hline Staphylococcus aureus & 2 & 7 & 4 & $13(9)$ & 1.6 \\
\hline Enterococcus faecalis & 5 & 3 & 3 & $11(8)$ & 1.4 \\
\hline Streptococcus spp. & $3^{a}$ & $2^{b}$ & $1^{\mathrm{C}}$ & $6(4)$ & 0.7 \\
\hline Enterobacter cloacae & 3 & 1 & 0 & $4(3)$ & 0.5 \\
\hline Enterococcus faecium & 2 & 0 & 1 & $3(2)$ & 0.4 \\
\hline Acinetobacter spp. & 1 & 2 & 0 & $3(2)$ & 0.4 \\
\hline Serratia marcescens & 1 & 1 & 0 & $2(2)$ & 0.2 \\
\hline Total, $n$ (\%) & $72(51)$ & $40(29)$ & $28(20)$ & $140(100)$ & \\
\hline
\end{tabular}

BC, blood culture; MP, MagicPlex assay; CoNs, coagulase-negative staphylococci.

a Streptococci of viridians group (S. anginosus and S. gordonii) and one S. agalactiae.

${ }^{b}$ One $S$. agalactiae and one $S$. pneumoniae.

cS. constellatus.

pathogen (47/140, 33.6\%), followed by CoNS (16/140, 11.4\%), Candida spp. (14/140, 10\%), and S. aureus (13/140, 9.3\%).

BC identified 3 mixed infections: E. cloacae plus $K$. pneumoniae, C. glabrata plus S. haemolyticus, and P. aeruginosa plus S. epidermidis. MP detected 4 mixed infections: S. agalactiae plus $S$. aureus, E. coli plus $S$. epidermidis, $P$. aeruginosa plus $S$. marcescens, and E. coli plus E. gallinarum. One mixed infection (E. faecium plus S. haemolyticus) was identified by both methods.

Three mecA genes were detected among the 9 pathogenic CoNS identified by the two methods. Routine susceptibility testing detected 7 methicillin-resistant CoNS and 2 methicillinsusceptible strains. Only one $\operatorname{vanB}$ resistance marker was detected in a sample positive for E. faecalis only according to MP and not BC. Therefore, this result remained unconfirmed. No additional BC or other microbiological samples positive for E. faecalis were obtained from this patient.

As shown in Table 2, samples with microbial contaminants were more frequently observed with BC than MP: $81 / 809$ (10\%) vs. $39 / 809$ (4.8\%) $(P<0.001)$, respectively.

Blood samples in which only microbial contaminants were detected were considered as negative for further analysis. As a result, $132 / 809(16.3 \%)$ of the samples were considered positive for one or more relevant microorganism by BC and/or MP. The level of agreement between BC and MP was 87.1\% (705/809). Regarding the 28 samples positive according to both methods, the same pathogen was identified in 27 of the cases, with the remaining one sample showing inconsistent results: E. coli detected by MP and E. faecium by BC. The rate of positive results was higher for BC $(96 / 809,11.9 \%)$ than MP (64/809, 7.9\%). Considered BC the gold standard and considering negative the samples with only contaminants detected, the sensitivity,
TABLE 2 | Concordance of the results obtained by BC and MP.

\begin{tabular}{lcccc}
\hline & \multicolumn{4}{c}{ Number of samples } \\
\cline { 2 - 5 } & $\begin{array}{c}\text { BC } \\
\text { positive }\end{array}$ & $\begin{array}{c}\text { BC } \\
\text { negative }\end{array}$ & $\begin{array}{c}\text { BC- } \\
\text { contaminated }\end{array}$ & Total \\
\hline MP-positive & 28 & 31 & 5 & 64 \\
MP-negative & 62 & 574 & 70 & 706 \\
MP-contaminated & 6 & 27 & 6 & 39 \\
Total & 96 & 632 & 81 & 809 \\
\hline
\end{tabular}

BC, blood culture; MP, MagicPlex assay.

specificity, positive predictive value and negative predictive value of MP were 29.2\% (95\% CI, 20.6-39.5), 95\% (95\% CI, 9396.4), 43.8\% (95\% CI, 31.6-56.7), and 90.9\% (95\% CI, 88.592.8), respectively.

Additional clinical information, including underlying disease and the antibiotic or antifungal therapy administered on the day of sampling, was recorded for the patients with $36 \mathrm{MP}$ positive and BC-negative or contaminated results (Table 3). When comparing the percentage of patients with undergoing antimicrobial treatment at the time of sample collection between three groups: only BC-positive (12/68, 17.6\%), only MP-positive (17/36, 47.2\%), and BC and MP-positive (8/28, 28.6\%), there was significantly higher number of patients receiving antimicrobials in the group of only MP-positive $(P=0.002)$. Interestingly, 3 of the 17 patients with only an MP-positive sample had a BC positive for the same microorganism in the previous days, while in 5 patients, other microbiological samples were positive for the pathogen detected by MP. 
TABLE 3 | Additional information from 36 patients with MP-positive and BC-negative results.

\begin{tabular}{|c|c|c|c|c|}
\hline Setting & MP result & Clinical condition & $\begin{array}{l}\text { Other microbiological tests } \\
\text { positive for the same } \\
\text { pathogen }\end{array}$ & $\begin{array}{l}\text { Ongoing } \\
\text { antibiotic/antifungal } \\
\text { treatment }^{\mathrm{a}}\end{array}$ \\
\hline & Escherichia coli & $\begin{array}{l}\text { Subarachnoid hemorrhage Control BC } 3 \\
\text { days after catheter-related Pseudomonas } \\
\text { aeruginosa bacteremia }\end{array}$ & - & Ciprofloxacin \\
\hline & Staphylococcus aureus & Necrotizing fasciitis & $\begin{array}{l}\text { BC positive for } S \text {. aureus } 2 \text { days } \\
\text { before sampling }\end{array}$ & Cloxacillin \\
\hline & $\begin{array}{l}\text { Streptococcus } \\
\text { pneumoniae }\end{array}$ & $\begin{array}{l}\text { Acute myeloid leukemia with neutropenic } \\
\text { fever without a clinical focus }\end{array}$ & - & $\begin{array}{l}\text { Piperacillin-tazobactam, } \\
\text { Vancomycin }\end{array}$ \\
\hline & Escherichia coli & $\begin{array}{l}\text { Septic shock due to } S \text {. aureus cellulitis in a } \\
\text { cirrhotic patient. Ascites decompensation }\end{array}$ & $\begin{array}{l}\text { Wound smear positive for } S \text {. } \\
\text { aureus }\end{array}$ & Ceftazidime and Tigecycline \\
\hline & Escherichia coli & $\begin{array}{l}\text { Acute necrotizing pancreatitis with } \\
\text { peripancreatic abscess }\end{array}$ & - & Meropenem \\
\hline & Staphylococcus aureus & $\begin{array}{l}\text { Superinfection of Pulmonary contusion in } \\
\text { a polytrauma patient }\end{array}$ & $\begin{array}{l}\text { Tracheal aspirate positive for } S \text {. } \\
\text { aureus } 2 \text { days before sampling }\end{array}$ & Levofloxacin \\
\hline & Escherichia coli & Colonic perforation post-nephrectomy & - & Piperacillin-tazobactam \\
\hline & Enterobacter cloacae & $\begin{array}{l}\text { Intestinal obstruction and abdominal } \\
\text { sepsis secondary to inguinal hernia }\end{array}$ & - & Levofloxacin \\
\hline & Acinetobacter baumannii & $\begin{array}{l}\text { Post-operative fever (liver resection } 48 \mathrm{~h} \\
\text { before sampling) }\end{array}$ & - & - \\
\hline \multirow{11}{*}{$\begin{array}{l}\text { Emergency department } \\
(n=15)\end{array}$} & Staphylococcus aureus & $\begin{array}{l}\text { Stroke. Bronchoaspiration in a patient with } \\
\text { prior colonization with S. aureus. }\end{array}$ & - & - \\
\hline & $\begin{array}{l}\text { Streptococcus } \\
\text { agalactiae, Staphylococcus } \\
\text { aureus }\end{array}$ & Cellulitis & - & - \\
\hline & Escherichia coli & $\begin{array}{l}\text { HIV patient with prosthetic aortic valve } \\
\text { with progressive prurigo nodularis }\end{array}$ & - & Amoxicillin/clavulanic acid \\
\hline & Escherichia coli & Fever during hemodialysis & Urine culture positive for $E$. coli & Amoxicillin/clavulanic acid \\
\hline & Escherichia coli & $\begin{array}{l}\text { Acute exacerbation of chronic obstructive } \\
\text { pulmonary disease (COPD) }\end{array}$ & $\begin{array}{l}\text { Sputum sample positive for } E \text {. } \\
\text { coli }\end{array}$ & - \\
\hline & Enterococcus faecalis & Traveler's diarrhea & - & - \\
\hline & $\begin{array}{l}\text { Pseudomonas } \\
\text { aeruginosa }\end{array}$ & $\begin{array}{l}\text { Acute gastroenteritis and } \\
\text { community-acquired UTI }\end{array}$ & - & - \\
\hline & Staphylococcus aureus & Pneumonia & - & - \\
\hline & $\begin{array}{l}\text { Staphylococcus } \\
\text { aureus }\end{array}$ & $\begin{array}{l}\text { UTI in a patient with permanent bladder } \\
\text { catheter }\end{array}$ & - & Amoxicillin/clavulanic acid \\
\hline & Pseudomonas aeruginosa & Acute exacerbation of Crohn's disease. & - & - \\
\hline & Klebsiella pneumoniae & $\begin{array}{l}\text { Pneumocystis carinii pneumonia in an } \\
\text { AIDS patient }\end{array}$ & - & - \\
\hline
\end{tabular}


TABLE 3 | Continued

\begin{tabular}{|c|c|c|c|c|}
\hline Setting & MP result & Clinical condition & $\begin{array}{l}\text { Other microbiological tests } \\
\text { positive for the same } \\
\text { pathogen }\end{array}$ & $\begin{array}{l}\text { Ongoing } \\
\text { antibiotic/antifungal } \\
\text { treatment }^{\mathrm{a}}\end{array}$ \\
\hline & Escherichia coli & Acute exacerbation of COPD & - & - \\
\hline & Klebsiella pneumoniae & $\begin{array}{l}\text { Pneumocystis carinii pneumonia in an } \\
\text { AIDS patient. Bacteremia caused by } E \text {. } \\
\text { faecalis }\end{array}$ & - & - \\
\hline \multirow[t]{3}{*}{$\begin{array}{l}\text { Oncology and } \\
\text { hematology }(n=4)\end{array}$} & $\begin{array}{l}\text { Enterococcus faecalis (vanB } \\
\text { positive) }\end{array}$ & $\begin{array}{l}\text { Non-Hodgkin T-cell lymphoma. } \\
\text { Neutropenic fever }\end{array}$ & - & Levofloxacin \\
\hline & Escherichia coli & Acute myeloid leukemia. Neutropenic fever & - & - \\
\hline & Escherichia coli & $\begin{array}{l}\text { Stem cell transplanted patient due to } \\
\text { acute myeloid leukemia. Neutropenic fever }\end{array}$ & - & - \\
\hline
\end{tabular}

ICU, intensive care unit; BC, blood culture; MP, MagicPlex assay.

${ }^{a}$ Only antimicrobial/antifungal therapy potentially effective against pathogen detected and initiated before sampling.

\section{DISCUSSION}

Several molecular assays have been tested for the direct molecular identification of pathogens in blood samples (Lehmann et al., 2008; Wellinghausen et al., 2009; Bloos et al., 2012; Grif et al., 2012; Loonen et al., 2013; Nieman et al., 2016) However, few studies have focused on commercially available PCR-based tests other than the SeptiFast test for the detection of BSI (Kühn et al., 2011; Fitting et al., 2012). Recently, T2 magnetic resonance assay was evaluated to detect Candida spp. and some bacteria in whole blood (Mylonakis et al., 2015; Snyder et al., 2017; Peker et al., 2018). In the present study, we evaluated the Magicplex ${ }^{\mathrm{TM}}$ Sepsis test (MP), comparing it with conventional BC. We observed that MP showed a sensitivity and specificity of 29.2 and $95 \%$, respectively. Only a few studies have evaluated the sensitivity and specificity of MP (Carrara et al., 2013; Loonen et al., 2013; Ljungström et al., 2015; Denina et al., 2016; Ziegler et al., 2016). Carrara et al. (2013), assessing 267 patients from ICU, emergency and hematology wards, reported an overall sensitivity of $65 \%$ for MP compared with $41 \%$ for BC. However, the authors calculated the sensitivities and specificities using a reference standard in which clinical data and other cultures were added to the BC results to see if a positive MP result represented a true BSI or not. Loonen et al. (2013), investigating 125 patients from the emergency department, reported a sensitivity of $37 \%$ and a positive predictive value (PPV) of $30 \%$ for MP, the low PPV resulting from many of the samples being positive for CoNS according to MP. Ljungström et al. (2015), analyzing samples from 375 patients with suspected sepsis collected from emergency wards, excluded suspected contaminants such as CoNS. They reported a sensitivity of $64 \%$ and specificity of $96 \%$ for MP. However, if they had included all the MP and BC results, the sensitivity of MP would have been $38 \%$, PPV $17 \%$, and specificity
$65 \%$. Taking into account all these results, the MP test could be useful in some clinical setting, such as among patients with undergoing antimicrobial treatment and negative blood cultures. Nevertheless, a low sensitivity demonstrated limits its use as a part of routine diagnostic algorithm. The low sensitivity of MP is probably due to the low bacterial concentration in whole blood and the low sample volume of $1 \mathrm{ml}$ used. There are several strategies intended to improve bacterial recovery, such as removing or significantly reducing the amount of human DNA present in the whole blood sample. Nevertheless, this step is already included in the MP and SepsiTest assays. Another possibility is to introduce an additional incubation step prior to extraction (Serra et al., 2012). Although this approach can increase microbial concentrations, it lengthens the whole process and compromises the main advantage of the molecular assays, which is the rapid procurement of results. Another strategy is to increase the initial volume of the blood sample $(>1 \mathrm{ml}$ ) (Hansen et al., 2009), which has been reported to give promising results and greatly improve the detection rates of PCR-based assays (Loonen et al., 2013) or increase the amount of bacterial DNA, as shown by Trung et al. (2016).

We observed 36 samples that were positive according to MP and negative according to $\mathrm{BC}$. This could have been due to the fact that almost half of these samples were obtained from patients on antibiotic treatment, which could explain the negative $\mathrm{BC}$ results. Unfortunately, the data about the start time and duration of antimicrobial treatment was not collected; therefore more detailed analysis of the treatment impact on BC and MP positivity could not be performed. The presence of cell-free DNA or non-viable microorganisms or even contaminating DNA could explain the other 19 discordant results (Opota et al., 2015).

Importantly, MP detected 5 out of the 14 Candida spp. and 11 out of the $13 \mathrm{~S}$. aureus isolates in our study. Early detection 
of these two pathogens is essential due to the high mortality rates and risk of haematogenous complications associated with these microbes. In addition, some Candida requires a longer time for growth in $\mathrm{BC}$ than other pathogens, delaying the initiation of treatment by several days. Candida spp. was the third most frequently occurring pathogen detected in our study. As expected, most of the positive samples were obtained from ICU patients. We detected a small number of resistance genes. Although the three mecA genes detected by MP were confirmed by routine susceptibility testing, in four cases of CoNS methicillin-resistant by routine susceptibility testing mecA gene was not detected by MP. Furthermore, the only van $B$-positive $E$. faecalis detected by MP was not isolated by $\mathrm{BC}$. Therefore, the accuracy of MP in detecting resistance genes should be further evaluated and probably is necessary the second molecular assay to confirm discordant results due to low predictor value of some phenotypic testing for detection of methicillin resistance.

Despite the many advantages of molecular assays, these tests have several important limitations. First, these methods require specialized equipment and technical experience and are usually expensive. The MP test also has several manual steps that make it laborious and increase the risk of possible contamination. Moreover, its low sensitivity makes its implementation as a routine test difficult in clinical microbiology laboratories. Finally, the sensitivity and specificity of molecular assays vary according to the test, the extraction method, the algorithm used to evaluate the results, the comparative method and the study population. Data published to date support the use of PCR-based tests for specific groups of patients, such as critically ill patients in ICU, those with suspected candidaemia or patients receiving broadspectrum antibiotics (von Lilienfeld-Toal et al., 2009; Bravo et al., 2011). There is no consensus about the interpretation of BCnegative and PCR-positive results (low pathogen concentrations, non-viable bacteria and DNAemia, etc.). Further studies are needed to evaluate the role of new molecular assays in the routine microbiological diagnosis of BSI. The main strengths of our study are: the higher sample number comparing with previous reports; patients included were not only from emergency departments but also from ICU and oncology/hematology; clinical conditions and antimicrobial treatment of patients with positive results detected only by PCR was investigated.

The main limitation of this study is that discordant only MP positive results were considered as false positive due to the use of $\mathrm{BC}$ as comparator. $\mathrm{BC}$ lacks sensitivity and the second molecular assay should be used to evaluate discordant results.

In conclusion, sepsis is a time-dependent disease that requires early diagnosis and prompt appropriate treatment to improve prognosis. The MP assay provides results within $6 \mathrm{~h}$, thereby significantly reducing the amount of time for diagnosis and seems to be especially useful in patients on antimicrobial treatment. Nevertheless, the assay has to be optimized, mainly to improve the sensitivity and also including other significant microorganisms within the panel. Greater automation is necessary to facilitate introduction of the assay into routine laboratory workflow and to reduce turnaround time.
Furthermore, the microbial detection limits of the molecular assay need to be improved, probably by new extraction protocols and greater sample volumes to improve the positive and negative predictive power so that it can be a useful tool in clinical practice, especially regarding its impact on antibiotic use.

\section{DATA AVAILABILITY}

The raw data supporting the conclusions of this manuscript will be made available by the authors, without undue reservation, to any qualified researcher. Requests to access the datasets should be directed to Catia Cillóniz.

\section{AUTHOR CONTRIBUTIONS}

CC, YZ, and JV had full access to all data in the study, and take full responsibility for its integrity, accuracy, and analysis. YZ, CC, NC-T, JH, MA, AV, CM, AS, JM, FM, and JV study concept and design, and acquisition, analysis, or interpretation of data, and critical revision of the manuscript for important intellectual content, and administrative, technical, or material support. CC, $\mathrm{YZ}$, and JV drafting of the manuscript and study supervision, and statistical analysis.

\section{FUNDING}

This study was supported by the Ministerio de Economía y Competitividad, Instituto de Salud Carlos III, and cofinanced by the European Regional Development Fund (ERDF) A Way to Achieve Europe and the Spanish Network for Research in Infectious Diseases (REIPI RD12/0015). This study was also supported by grant 2014SGR653 from the Departament d'Universitats, Recerca i Societat de la Informació of the Generalitat de Catalunya, as well as by funding from the Innovative Medicines Initiative (COMBACTE, grant agreement 115523), Ciber de Enfermedades Respiratorias (CibeRes CB06/06/0028), 2009 Support to Research Groups of Catalonia 911 and IDIBAPS (CERCA Programme/Generalitat de Catalunya). The funding sources had no role in the design or conduct of the study; collection, management, analysis, or interpretation of the data; preparation, review, or approval of the manuscript; or decision to submit the manuscript for publication. CC is the recipient of a postdoctoral grant (Strategic Plan for Research and Innovation in Health - PERIS 2016-2020). $\mathrm{CM}$ was working with the IZASA-Werfen Group during the undertaking of this study.

\section{ACKNOWLEDGMENTS}

We are indebted to all our medical and nursing colleagues for their assistance and cooperation in this study. All the reagents for the Magicplex ${ }^{\mathrm{TM}}$ Sepsis test were provided by the IZASA-Werfen Group. Our article has been released as a pre-print at https://www.biorxiv.org/content/early/2018/07/23/ 374736 (Zboromyrska et al., 2018). 


\section{REFERENCES}

Bloos, F., Sachse, S., Kortgen, A., Pletz, M. W., Lehmann, M., Straube, E., et al. (2012). Evaluation of a polymerase chain reaction assay for pathogen detection in septic patients under routine condition: an observational study. PLOS ONE 7:e46003. doi: 10.1371/journal.pone.0046003

Bravo, D., Blanquer, J., Tormo, M., Aguilar, G., Borrás, R., Solano, C., et al. (2011). Diagnostic accuracy and potential clinical value of the lightcycler septifast assay in the management of bloodstream infections occurring in neutropenic and critically ill patients. Int. J. Infect. Dis. 15, e326-e331. doi: 10.1016/j.ijid.2011.01.003

Candel, F. J., Borges, S. á. M., Belda, S., Bou, G., Del Pozo, J. L., Estrada, O., et al. (2018). Current aspects in sepsis approach. turning things around. Rev. Espanola. Quimioter. 31, 298-315.

Carrara, L., Navarro, F., Turbau, M., Seres, M., Morán, I., Quintana, I., et al. (2013). Molecular diagnosis of bloodstream infections with a new dual-priming oligonucleotide-based multiplex PCR assay. J. Med. Microbiol. 62(Pt 11), 1673-1679. doi: 10.1099/jmm.0.064758-0

Denina, M., Scolfaro, C., Colombo, S., Calitri, C., Garazzino, S., Barbui Anna, A., et al. (2016). Magicplex(TM) sepsis real-time test to improve bloodstream infection diagnostics in children. Eur. J. Pediatr. 175, 1107-1111. doi: 10.1007/s00431-016-2745-3

Fenollar, F., and Raoult, D. (2007). Molecular diagnosis of bloodstream infections caused by non-cultivable bacteria. Int. J. Antimicrob. Agents 30(Suppl 1), S7-S15. doi: 10.1016/j.ijantimicag.2007.06.024

Ferrer, R., Martin-Loeches, I., Phillips, G., Osborn, T. M., Townsend, S., Dellinger, R. P., et al. (2014). Empiric antibiotic treatment reduces mortality in severe sepsis and septic shock from the first hour: results from a guidelinebased performance improvement program. Crit. Care Med. 42, 1749-1755. doi: 10.1097/CCM.0000000000000330

Fitting, C., Parlato, M., Adib-Conquy, M., Memain, N., Philippart, F., Misset, B., et al. (2012). DNAemia detection by multiplex PCR and biomarkers for infection in systemic inflammatory response syndrome patients. PLOS ONE 7:e38916. doi: 10.1371/journal.pone.0038916

Grif, K., Fille, M., Würzner, R., Weiss, G., Lorenz, I., Gruber, G., et al. (2012). Rapid detection of bloodstream pathogens by real-time PCR in patients with sepsis. Wien Klin Wochenschr. 124, 266-270. doi: 10.1007/s00508-0120159-4

Hansen, W. L. J., Bruggeman, C. A., and Wolffs, P. F. G. (2009). Evaluation of new preanalysis sample treatment tools and DNA isolation protocols to improve bacterial pathogen detection in whole blood. J. Clin. Microbiol. 47, 2629-2631. doi: 10.1128/JCM.00821-09

Kühn, C., Disqué C., Mühl, H., Orszag, P., Stiesch, M., and Haverich, A. (2011). Evaluation of commercial universal rRNA gene PCR plus sequencing tests for identification of bacteria and fungi associated with infectious endocarditis. $J$. Clin. Microbiol. 49, 2919-2923. doi: 10.1128/JCM.00830-11

Kumar, A., Roberts, D., Wood, K. E., Light, B., Parrillo, J. E., Sharma, S., et al. (2006). Duration of hypotension before initiation of effective antimicrobial therapy is the critical determinant of survival in human septic shock. Crit. Care Med. 34, 1589-1596. doi: 10.1097/01.CCM.0000217961.75225.E9

Lehmann, L. E., Hunfeld, K.-P., Emrich, T., Haberhausen, G., Wissing, H., Hoeft, A., et al. (2008). A multiplex real-time PCR assay for rapid detection and differentiation of 25 bacterial and fungal pathogens from whole blood samples. Med. Microbiol. Immunol. (Berl). 197, 313-324. doi: 10.1007/s00430-007-0063-0

Leitner, E., Kessler, H. H., Spindelboeck, W., Hoenigl, M., Putz-Bankuti, C., Stadlbauer-Köllner, V., et al. (2013). Comparison of two molecular assays with conventional blood culture for diagnosis of sepsis. J. Microbiol. Methods 92, 253-255. doi: 10.1016/j.mimet.2012.12.012

Ljungström, L., Enroth, H., Claesson, B. E. B., Ovemyr, I., Karlsson, J., Fröberg, B., et al. (2015). Clinical evaluation of commercial nucleic acid amplification tests in patients with suspected sepsis. BMC Infect. Dis. 15:199. doi: 10.1186/s12879-015-0938-4

Loonen, A. J. M., Bos, M. P., van Meerbergen, B., Neerken, S., Catsburg, A., Dobbelaer, I., et al. (2013). Comparison of pathogen DNA isolation methods from large volumes of whole blood to improve molecular diagnosis of bloodstream infections. PLoS ONE 8:e72349. doi: 10.1371/journal.pone.0072349

Mylonakis, E., Clancy, C. J., Ostrosky-Zeichner, L., Garey, K. W., Alangaden, G. J., Vazquez, J. A., et al. (2015). T2 magnetic resonance assay for the rapid diagnosis of candidemia in whole blood: a clinical trial. Clin. Infect. Dis. 60, 892-899. doi: $10.1093 /$ cid/ciu959

Nieman, A. E., Savelkoul, P. H. M., Beishuizen, A., Henrich, B., Lamik, B., MacKenzie, C. R., et al. (2016). A prospective multicenter evaluation of direct molecular detection of blood stream infection from a clinical perspective. $B M C$ Infect. Dis. 16:314. doi: 10.1186/s12879-016-1646-4

Opota, O., Jaton, K., and Greub, G. (2015). Microbial diagnosis of bloodstream infection: towards molecular diagnosis directly from blood. Clin. Microbiol. Infect. 21, 323-331. doi: 10.1016/j.cmi.2015.02.005

Peker, N., Couto, N., Sinha, B., and Rossen, J. W. (2018). Diagnosis of bloodstream infections from positive blood cultures and directly from blood samples: recent developments in molecular approaches. Clin Microbiol Infect. 24, 944-955. doi: 10.1016/j.cmi.2018.05.007

Serra, J., Rosello, E., Figueras, C., Pujol, M., Peña, Y., Céspedes, P., et al. (2012). Clinical evaluation of the magicplex sepsis real-time test (Seegene) to detect candida DNA in pediatric patients. Crit. Care. 16(Suppl 3):P42. doi: $10.1186 / \mathrm{cc} 11729$

Sinha, M., Jupe, J., Mack, H., Coleman, T. P., Lawrence, S. M., and Fraley, S. I. (2018). Emerging technologies for molecular diagnosis of sepsis. Clin. Microbiol. Rev. 31:e00089-17. doi: 10.1128/CMR.00089-17

Snyder, J. L., Giese, H., Bandoski-Gralinski, C., Townsend, J., Jacobson, B. E., Shivers, R., et al. (2017). T2 magnetic resonance assay-based direct detection of three lyme disease-related borrelia species in whole-blood samples. J. Clin. Microbiol. 55, 2453-2461. doi: 10.1128/JCM.00510-17

Trung, N. T., Hien, T. T. T., Huyen, T. T. T., Quyen, D. T., Van Son, T., Hoan, P. Q., et al. (2016). Enrichment of bacterial DNA for the diagnosis of blood stream infections. BMC Infect. Dis. 16:235. doi: 10.1186/s12879-016-1568-1

von Lilienfeld-Toal, M., Lehmann, L. E., Raadts, A. D., Hahn-Ast, C., Orlopp, K. S., Marklein, G., et al. (2009). Utility of a commercially available multiplex realtime PCR assay to detect bacterial and fungal pathogens in febrile neutropenia. J. Clin. Microbiol. 47, 2405-2410. doi: 10.1128/JCM.00491-09

Wellinghausen, N., Kochem, A.-J., Disqué C., Mühl, H., Gebert, S., Winter, J., et al. (2009). Diagnosis of bacteremia in whole-blood samples by use of a commercial universal $16 \mathrm{~S}$ rRNA gene-based PCR and sequence analysis. J. Clin. Microbiol. 47, 2759-2765. doi: 10.1128/JCM.00567-09

World Health Organization (2018). Sepsis. World Health Organization. Available online at: http://www.who.int/sepsis/en/ (Accessed Oct 15, 2018)

Yagupsky, P., and Nolte, F. S. (1990). Quantitative aspects of septicemia. Clin. Microbiol. Rev. 3, 269-279.

Zboromyrska, Y., Cilloniz, C., Cobos-Trigueros, N., Almela, M., Hurtado, J. C., Vergara, A., et al. (2018). MagicplexTM Sepsis real-time test for the rapid diagnosis of bloodstream infections in adults. bioRxiv 1:374736. doi: $10.1101 / 374736$

Ziegler, I., Fagerström, A., Strålin, K., and Mölling, P. (2016). Evaluation of a commercial multiplex PCR assay for detection of pathogen DNA in blood from patients with suspected sepsis. PLoS ONE 11:e0167883. doi: 10.1371 /journal.pone. 0167883

Conflict of Interest Statement: The authors declare that the research was conducted in the absence of any commercial or financial relationships that could be construed as a potential conflict of interest.

Copyright (c) 2019 Zboromyrska, Cillóniz, Cobos-Trigueros, Almela, Hurtado, Vergara, Mata, Soriano, Mensa, Marco and Vila. This is an open-access article distributed under the terms of the Creative Commons Attribution License (CC BY). The use, distribution or reproduction in other forums is permitted, provided the original author(s) and the copyright owner(s) are credited and that the original publication in this journal is cited, in accordance with accepted academic practice. No use, distribution or reproduction is permitted which does not comply with these terms. 